\title{
Comparative Evaluation of Korean White Ginseng and Red Ginseng Efficacies in a Mouse Model of Ischemia/Reperfusion-Induced Stroke
}

Myungho Jin

Dong Eui University College of Korean Medicine

Kyung-Min Kim

Dong Eui University College of Korean Medicine

Chiyeon Lim

Dongguk University College of Medicine

Suin Cho ( $D$ sicho@pusan.ac.kr)

Pusan National University School of Korean Medicine https://orcid.org/0000-0001-8507-1382

\section{Young Kyun Kim}

Dong Eui University College of Korean Medicine

\section{Research}

Keywords: Korean ginseng, Panax ginseng Meyer, stroke, anti-inflammation, anti-apoptosis

Posted Date: December 30th, 2020

DOI: https://doi.org/10.21203/rs.3.rs-136214/v1

License: (9) This work is licensed under a Creative Commons Attribution 4.0 International License. Read Full License 


\section{Abstract}

Background: Stroke is a condition characterized by brain tissue damage owing to a decrease in the brain's oxygen supply due to blocked blood vessels, and $80 \%$ of all strokes are classified as cerebral infarction. Notably, the incidence rate tends to increase with increasing age. In this study, we compared the efficacy of white ginseng (WG) and red ginseng (RG) extracts (WGex and RGex, respectively) in an ischemic stroke mouse model and confirmed the underlying mechanisms of action.

Methods: Mice were orally administered WGex or RGex $1 \mathrm{~h}$ before performing middle cerebral artery occlusion (MCAO) for $2 \mathrm{~h}$; the size of the infarct area was measured $24 \mathrm{~h}$ after MCAO. The neurological deficit score was evaluated, the efficacy of the two drugs was compared, and the mechanism of action was confirmed using methods such as tissue staining and protein quantification.

Results: In the MCAO-induced ischemic stroke mouse model, WGex and RGex showed neuroprotective effects in the cortical region, with RGex demonstrating a generally stronger efficacy than WGex. Furthermore, it was confirmed that ginsenoside $\mathrm{Rg} 1$, a representative indicator substance, was not involved in mediating the effects of WGex and RGex.

Conclusion: WGex and RGex inhibited brain injury attributed to ischemia/reperfusion, with RGex revealing a more potent effect. At $1,000 \mathrm{mg} / \mathrm{kg}$ body weight, only RGex reduced cerebral infarction and edema, and both anti-inflammatory and anti-apoptotic pathways were involved in mediating these effects.

\section{Background}

Radix Ginseng, originating from Panax ginseng C.A. Meyer, is considered the most popular herb in traditional Korean medicine and is frequently used worldwide to treat a variety of diseases [1]. Ginseng is used as a general tonic to promote health in Asian countries, and the pharmacological properties of ginseng are attributed to ginsenosides isolated from ginseng [2]. Ginseng extracts contain numerous physiologically active ingredients, and ginsenosides, the main ingredients in ginseng, are thought to possess anti-allergic, antioxidant, and immunostimulating properties [3].

In traditional medicine, two traditional Korean ginseng preparations, white ginseng (WG) and red ginseng (RG), are speculated to possess different biological activities. WG is produced by sun-drying fresh ginseng, and RG is produced by steaming fresh or dried ginseng for a reasonable period, followed by drying until the moisture content is less than $15 \%$ [4].

Several researchers have reported that the steaming process increases bioactive ingredients in ginseng when compared with those in non-steamed samples [4-6]. However, comparative studies evaluating WG and RG in animal models of stroke are limited.

Cerebrovascular disorders (CVDs) are a leading cause of death worldwide, reportedly affected by abnormalities of the heart and blood vessels. Among CVDs, acute ischemic stroke is considered the 
leading cause of morbidity and mortality in modern society [7-11]. Ischemic stroke can be characterized by arterial embolic or thrombotic occlusion, resulting in brain inflammation and cell death. Notably, white blood cells delivered via the blood are known to infiltrate the brain to activate inflammation, and then cell death signals are activated by the permeability of the outer mitochondrial membrane [12-14].

Thrombolytic drugs such as anticoagulants and antiplatelets are used as therapeutic agents to treat ischemic stroke, a condition that can cause morbidity and disability and impose a heavy burden on patients by increasing medical expenses and necessitating rehabilitation and long-term care $[15,16]$. Therefore, further research on the prevention and treatment of ischemic stroke is urgently needed $[17,18]$.

Typically, there are two types of surgical procedures to induce ischemic stroke in rodents, by temporarily blocking the middle cerebral artery (MCA): Koizumi's and Longa's methods [19-22]. Koizumi's method inserts monofilaments into the MCA via the common carotid artery (CCA), whereas Longa's method inserts filaments via the external carotid artery (ECA) [23]; however, Koizumi's method is commonly employed to establish a stroke model in mice.

Although several studies have reported [24-26] that ginseng or its constituents have the potential to inhibit brain damage, its effects, as well as its mechanisms of action, in animal models of cerebral infarction have rarely been reported. In this study, we investigated the differences and mechanisms underlying the protective effects of WG and RG on cerebral injury induced by ischemia/reperfusion of MCA blood flow.

\section{Materials And Methods}

\section{Animals}

Six-week-old C57BL/6 male mice (Samtako Bio, Osan, Korea), weighing 20-22 g, were housed in polypropylene cages at $24 \pm 4^{\circ} \mathrm{C}$, under a $12 \mathrm{~h}$ light/dark cycle for 1 week prior to the experiment. The experimental animals were fed a standard pellet diet and water ad libitum. All experimental procedures performed in the present study were approved by the Ethics Committee for Animal Care and Use at Pusan National University (Approval No. PNU 2019-2485), certified by the Korean Association of Laboratory Animal Care.

\section{Reagents}

Cresyl violet (CV) and 2,3,5-triphenyl-tetrazolium chloride (TTC) were purchased from Sigma-Aldrich (St. Louis, MO, USA). Phosphate-buffered saline (PBS) was purchased from Bio Basic Inc. (Markham, Ontario, Canada). Saline was purchased from JW Pharmaceutical Co., Ltd. (Seoul, Korea). The optimal cutting temperature (OCT) compound cryostat embedding medium was obtained from Thermo Fisher Scientific (Waltham, MA, USA). Methanol was obtained from SK Chemicals (Ulsan, Korea). The protein extraction solution was obtained from iNtRON (Seongnam-si, Gyeonggi-do, Korea). Primary antibodies against phospho-c-Jun N-terminal kinase (p-JNK), JNK, p-nuclear factor of kappa light polypeptide gene enhancer in $\mathrm{B}$-cells inhibitor alpha ( $\mathrm{p}-\mathrm{I} \mathrm{KBa}), \mathrm{I} \mathrm{KB}$, manganese superoxide dismutase (Mn-SOD), and $\beta$-actin were 
obtained from Cell Signaling Technology (Danvers, MA, USA). Secondary antibodies for goat anti-rabbit IgG pAb, goat anti-mouse IgG, and pAb were purchased from Enzo Life Sciences Inc. (Farmingdale, NY, USA). The BCA reagent, bovine serum albumin (BSA) standard, and enhanced chemiluminescence (ECL) western blotting chemiluminescent substrate were obtained from Thermo Fisher Scientific (Waltham, MA, USA).

\section{Preparation and high-pressure liquid chromatography (HPLC) analysis of WG and RG extracts}

Standardized WG and RG, manufactured from a 5-year-old ginseng sample, were obtained from Gwangmyung Natural Pharmaceutical Co. (Busan, Korea), and voucher specimens (No. 201 KWG and 201KRG) were deposited at the Herbarium of School of Korean Medicine, Pusan National University. For both WG and RG, $200 \mathrm{~g}$ of each were finely ground and extracted with 10 times the volume of $99 \%$ methanol at $25^{\circ} \mathrm{C}$ for 3 days; this was repeated three times. After filtration using filter paper (Advantec, USA), methanol was removed using a vacuum evaporator (Eyela, Japan) at $45^{\circ} \mathrm{C}$, and then stored at $-20^{\circ} \mathrm{C}$ until use. The final lyophilized WG extract (WGex) and RG extract (RGex) from WG and RG weighed $24.2 \mathrm{~g}$ and $25.3 \mathrm{~g}$, yielding $12.1 \%$ and $12.7 \%$, respectively.

For quality assurance of WGex and RGex, each extract was subjected to HPLC analysis. To obtain a fingerprint of extracts used in this experiment, we determined the presence of ginsenoside Rg1, a main component of ginseng, using an HPLC system (Shimadzu, Kyoto, Japan) consisting of an LC-20AD pump, a SIL-20A autosampler, an SPD-M20A detector, and a CTO-20A column oven. The samples were separated using a YMC-Triart C18 column. The mobile phase and elution systems are listed in Table 1.

\section{Induction of transient middle cerebral artery occlusion (tMCAO)}

In the present study, Koizumi's method was modified at our laboratory, and the modified method was performed in mice; detailed protocols and materials have been previously reported [27]. In brief, for left hemispheric MCAO, anesthesia was induced by inhalation of $1.5-2 \%$ isoflurane in $\mathrm{N}_{2} \mathrm{O} / \mathrm{O}_{2}(70 \% / 30 \%)$ until mice showed no response to mechanical stimuli. Following the induction of anesthesia, the mice were placed on a heating pad (Harvard Instruments, Boston, MA, USA). During the tMCAO surgery, the body temperature of mice was monitored using a rectal temperature probe and maintained at $37 \pm 1{ }^{\circ} \mathrm{C}$. The surgical site, as well as the chest area of mice, were disinfected with povidone and $70 \%$ ethyl alcohol. Then, the left side of the skull, near the ear, was exposed using surgical mesh, and an optic fiber was attached to the skull to monitor the relative cerebral blood flow ( $\mathrm{rCBF}$ ). A midline incision was made on the neck, and soft tissues over the trachea were gently retracted. The ECA, distal CCA (dCCA), and proximal CCA (pCCA) were loosely knotted with 4-0 suture silk, and the ECA and CCA were carefully isolated from the vagus nerve. The ECA and DCCA were ligated before clamping of the internal carotid artery (ICA). Then, an 8-0 monofilament suture line (Ethicon, CA, USA) coated with silicon was inserted into the MCA through the perforated CCA. For the tMCAO operation, the monofilament was retracted when the predetermined occlusion time ended in the present experiment ( $2 \mathrm{~h}$ tMCAO). To complete the surgical process, the incised region was sutured and disinfected, and the mice were maintained in a recovery cage 
for 30 min. All surgeries were performed using laser Doppler flowmetry (Moor Instruments Ltd., Devon, UK) to detect rCBF and confirm successful occlusion and reperfusion.

\section{Pretreatment with WGex and RGex}

Experimental mice were randomly divided into eight groups as follows: 100,300 , and $1000 \mathrm{mg} / \mathrm{kg} \mathrm{WGex-}$ treated; 100, 300, and 1000 RGex-treated; PBS-treated control; sham-operated sham group. Each group consisted of 15 mice (Supplementary Fig. 1, Fig. S1). In Korean medicine, 30 mg/kg has been recommended as the daily dose of WG and RG extract in humans; in mice, the equivalent dose was determined as $400 \mathrm{mg} / \mathrm{kg}$. Thus, the dose range varied between 100 and $1000 \mathrm{mg} / \mathrm{kg}$. For each WGex and RGex concentration prepared in PBS, the solution was orally administered using an oral zonde $1 \mathrm{~h}$ before MCAO induction, with sham and control mice orally administered the same volume of PBS. After $24 \mathrm{~h}$ of MCAO induction, the mice were sacrificed to perform several assays. A schematic diagram of the experiment is shown in Fig. 1.

\section{Infarct and edema area measurements}

TTC staining can be assumed as a function of mitochondria and is reportedly an important marker of ischemic volume following ischemic stroke. The mice were anesthetized by $\mathrm{CO}_{2}$ respiration, and blood was collected to obtain serum $\left(25^{\circ} \mathrm{C}\right.$ room temperature, $\left.10 \mathrm{~min}, 13,000 \times \mathrm{g}\right)$. Then, the mouse brain was harvested to measure the total infarct volume, and the olfactory bulb and cerebellum were isolated. Serial coronal sections ( $1 \mathrm{~mm}$ thickness) were stained with $2 \%$ TTC solution to assess infarct volume. Next, the sections were digitized using a digital camera and a tablet, and the ischemic area and non-infarct tissue were separated using an image analysis system (Digimizer, Ostend, Belgium).

Areas of brain edema were calculated by dividing the total infarction volumes in ipsilateral hemispheres by brain edema indices using TTC-stained brain sections. The formula used to calculate brain edema indices is as follows:

Brain edema index $=$ total volume of ipsilateral hemisphere / total volume of the contralateral hemisphere

\section{Neurological deficit score (NDS) measurement}

In mice, the behavioral changes were measured using a 5-scale assessment after surgery, and the characterization of each score was described as follows: Score 0 , mouse presenting behavior similar to a normal mouse; Score 1, spontaneous exercise could be performed, but the behavior was slower; Score 2, slightly reduced temperature and reduced $(2-3 \mathrm{~g})$ body weight, and mice moved toward the contralateral direction; Score 3: reduced body temperature and weight (3-4 g), and mice demonstrated sensitivity to mechanical stimuli, including pain, walking, or circling to the right; Score 4, reduced body temperature and weight (4-5 g), with mice failing to exhibit spontaneous behavior or demonstrate extreme sensitivity to mechanical stimuli.

\section{Sacrifice and cardiac perfusion for harvesting the brain}


The mouse abdomen was incised, and cardiac perfusion with PBS was performed. In brief, the pulmonary artery was blocked, the left ventricle was pierced with a 21 gauge needle; then, the needle was fixed in the ascending aorta. Immediately after perfusion, the right atrium was incised using scissors. PBS and $4 \%$ paraformaldehyde (PFA) solution were used for perfusion and fixation, respectively. Post-fixation, the brain was soaked in $10 \%$ PFA with $10-30 \%$ sucrose at $4^{\circ} \mathrm{C}$ for 3 days, followed by cryosectioning for appropriate staining.

\section{Frozen sections of mice brain}

Mouse brains were sequentially placed in $10 \%, 20 \%$, and $30 \%$ sucrose solutions before freezing (in OCT compound), and then stored at $-80^{\circ} \mathrm{C}$. For each mouse group, brain sections were obtained using a cryostat (Leica, Wetzlar, Germany) at a thickness of $30 \mu \mathrm{m}$, and the sections were then placed on glass slides for $12 \mathrm{~h}$ and stored at $-80^{\circ} \mathrm{C}$ until use.

\section{Hematoxylin and eosin (H\&E) staining}

For each mouse group, the brain sections on slides were allowed to dry on a slide warmer; then, the slides were dipped into $80 \%$ ethyl alcohol. The slides were immersed in a hematoxylin solution for $5 \mathrm{~min}$, followed by gently washing with distilled water. Next, the slides were soaked in acid alcohol (1\%) two times, and immersed in a lithium carbonate solution. Then, the sections were washed and slides were dipped in eosin solution for $30 \mathrm{sec}$. The slides were immersed in graded ethyl alcohol concentrations ( $95 \%$ and $100 \%$ sequentially) for 1 min, placed in xylene, mounted, and then observed under a light microscope. The density of H\&E-positive cells was measured in the cortical region of mouse brains using the ImageJ program (NIH, MD, USA).

\section{Nissl staining}

For each mouse group, the sections on glass slides were allowed to dry on a slide warmer. Then, the slides were immersed in an alcohol:chloroform solution overnight. The slides were incubated in $0.1 \% \mathrm{CV}$ solution for $10 \mathrm{~min}$ at $40^{\circ} \mathrm{C}$ in an incubator. Then, the slides were quickly washed with distilled water, placed in graded ethyl alcohol ( $95 \%$ and $100 \%$ sequentially) for 5 min, sealed with a coverslip and mounting solution, and then observed under a light microscope. The density of neuronal cells was measured in the cortical region of the mouse brains using the ImageJ program ( $\mathrm{NIH}, \mathrm{MD}, \mathrm{USA})$.

\section{Western blot analysis}

Proteins in the ipsilateral brain hemisphere were isolated using a protein extraction solution. Brain tissue lysates were obtained by centrifugation at $15,871 \times \mathrm{g}$ for $10 \mathrm{~min}$ at $4^{\circ} \mathrm{C}$. The total protein level in the supernatant was quantitated using the BSA method. In brief, $30 \mu \mathrm{m}$ of the protein was developed and separated by SDS-PAGE, and then transferred onto PVDF membranes (Millipore, Darmstadt, Germany). The PVDF membranes were blocked with $5 \%$ skim milk in TBST buffer (Tris-buffered saline, $0.1 \%$ Tween 20) for $1 \mathrm{~h}$ at $25^{\circ} \mathrm{C}$, and then incubated overnight at $4^{\circ} \mathrm{C}$ with primary antibodies against inducible nitric oxide synthase (iNOS), p-IkBa, IkBa, p-JNK (1:1000), JNK (1:1000), Mn-SOD (1:1000), and $\beta$-actin 
(1:1000). After overnight incubation, secondary antibodies for HRP-conjugated goat anti-rabbit IgG, pAb (1:5000), and HRP-conjugated goat anti-mouse IgG pAb (1:3000) were added for $1 \mathrm{~h}$ at $25^{\circ} \mathrm{C}$. After incubation, the membranes were treated with an ECL solution kit, and the expression levels of each protein were detected using a luminescent analyzer system (Amersham ${ }^{\mathrm{TM}}$ Imager 600, Buckinghamshire, UK). The densities of all detected bands were analyzed using the ImageJ program ( $N I H, M D, U S A)$.

\section{Statistical analysis}

One-way analysis of variance (ANOVA) was performed, followed by the Holm-Sidak test to determine the significance of differences among groups using Sigmaplot 12.0 (Systat Software Inc., CA, USA). Data are expressed as the mean \pm standard deviation (SD), and a $p<0.05$ was deemed significant.

\section{Results}

\section{Analytical comparisons of WGex and RGex and their standard, ginsenoside Rg1}

Ginsenoside Rg1 is the main derivative of radix ginseng, and its structure is shown in Figure 2a. The presence of ginsenoside Rg1 in WGex and RGex was confirmed by HPLC (Fig. 2b, 2c). Following quantitative measurement, a three-fold higher ginsenoside Rg1 concentration was detected in WGex than that in RGex (Table 2).

\section{Measurements of infarct volume, edema area, and NDS}

To determine the effects of ginseng extracts on ischemic stroke in mice, pretreatment with WGex and RGex was performed $1 \mathrm{~h}$ before the induction of ischemic stroke, and the effective dose was selected. Single doses of 100,300 , and $1,000 \mathrm{mg} / \mathrm{kg} /$ day were administered (treatment on the day of MCAO). Representative images of TTC-stained brain slices are shown in Fig. 3a. Among them, the most effective dosage selected for RGex was $1,000 \mathrm{mg} / \mathrm{kg}$ body weight (bw) (Fig. 3a). WGex had no effect on total infarct volume within the investigated dose range; however, the infarct volume tended to decrease in a dose-dependent manner (Fig. 3a). Following pretreatment with 1,000 mg/kg bw of RGex, the percentage of the total infarct volume in the ipsilateral hemisphere of the brain was $41.40 \pm 5.28 \%$, and that in the MCAO control group was $56.67 \pm 10.05 \%$.

Reduction in brain edema was observed in the RGex groups pretreated with 300 and $1,000 \mathrm{mg} / \mathrm{kg} / \mathrm{day}$ $\left(16.73 \pm 3.39 \mathrm{~mm}^{3}\right.$ and $18.60 \pm 1.82 \mathrm{~mm}^{3}$, respectively) when compared with the MCAO control group $\left(28.92 \pm 6.85 \mathrm{~mm}^{3}\right)$ (Fig. 3b).

For NDS, no significance was observed among the MCAO-induced groups (Fig. 3c); however, pretreatment with WGex and RGex (1,000 mg/kg bw) revealed lower scores than the low-dose treatment groups.

In anesthetized mice, we assessed rCBF during MCAO induction and reperfusion processes using a laser Doppler probe connected to an optic fiber, attached to the temporal surface of the skull. Assuming that the entire blood flow before CCA ligation was 100\%, CCA occlusion reduced CBF to approximately $59 \pm$ 
$6 \%$ of baseline levels. On occluding the MCA, rCBF values decreased to approximately $10 \pm 8 \%$, and no significant difference was observed among groups (Supplementary Fig. 2, Fig. S2).

\section{Morphological changes in neuronal cells}

To evaluate the neuroprotective effects of ginseng extracts, WGex and RGex, on ischemic stroke-induced neuronal damage, we investigated morphological changes in neuronal cells in MCAO-induced in the ipsilateral hemisphere of mouse brains. In the sham-operated group, H\&E-stained neuronal cells were observed as normally intact and showed morphologically well-arranged cytoplasm and nucleus. The MCAO group showed aberrant morphology, displaying an H\&E-negative area. Animal groups pretreated with ginseng extracts presented marginal recovery of neuronal damage (WGex, $74.33 \pm 5.86 \%$; RGex, $79.67 \% \pm 5.03 \%$ ), demonstrating similar cellular structure to that observed in the sham-operated group; however, on comparing the H\&E color intensity between groups, ginseng extracts showed no significant change when compared with the MCAO control group (Fig. 4a).

For all groups, the cell density on CV staining in the ipsilateral hemisphere of the brain is shown in Figure 4b. The cell density of the sham-operated group was $100.00 \pm 5.00 \%$ and that in the MCAO control group was $65.33 \pm 7.02 \%$. Following pretreatment with $1,000 \mathrm{mg} / \mathrm{kg}$ bw of WGex or RGex in MCAO-induced mice, the cell densities were $81.67 \pm 3.06 \%$ and $85.33 \pm 5.51 \%$, respectively (Fig. $4 \mathrm{~b}$ ). The cell densities in mouse brains pretreated with ginseng extracts were significantly higher than those of the control group (Fig. 4b). The MCAO control group presented cellular damage, with shrinkage and pyknotic nuclei (red arrowheads, Fig. 5b), whereas the ginseng extract-treated groups revealed neuronal cell recovery (arrows, normal neurons; black arrowheads, glial cells). Overall, when stained with CV, the ipsilateral cell density of all ginseng treated groups was significantly recovered (Fig. 5c, 5d).

\section{Expression of cell death related proteins in the ipsilateral cerebral cortex}

Reportedly, iNOS promotes inflammation and exerts a synergistic effect with other inflammatory mediators; in the brain, increased iNOS protein levels after ischemia cause NO production and DNA damage. Thus, inhibiting the activity of iNOS could be a key target for regulating inflammatory responses in the ischemic brain [28-30]. In the current study, pretreatment with $1,000 \mathrm{mg} / \mathrm{kg}$ bw RGex decreased ( $1.44 \pm 0.18$-fold $)$ the increased iNOS expression in brain damage induced by MCAO $(2.16 \pm 0.44$-fold $)$ (Fig. 6a).

Mitogen-activated protein kinase (MAPK), an important intracellular signal-mediating molecule, is involved in various cell activities, including cell proliferation, differentiation, survival, death, and deformation [31-35], and as a downstream signal of MAPK, JNK activates apoptotic pathways by upregulating pro-apoptotic genes [33-35]; increased JNK expression in the MCAO control group was inhibited by both WGex and RGex administration. The ratio of $p$-JNK/JNK expression was $1.00 \pm 0.15$ in the sham group, $10.06 \pm 3.49$ in the MCAO control group, and $5.82 \pm 1.26$ and $4.22 \pm 1.47$ in WGex and RGex pretreated groups, respectively (Fig. 6b). 
NF-KB participates in inflammasome regulation, and NF-KB proteins are present in the cytoplasm in association with regulatory proteins called inhibitors of $\mathrm{KB}(\mathrm{IkBs})$. The IkB proteins are phosphorylated and subsequently degraded in the proteasome, and degradation of $\mathrm{kBBs}$ allows translocation of NF-KB into the nucleus, thus promoting inflammatory responses [36,37]. The increased expression of $\mathrm{p}-\mathrm{lkBa}$ in the MCAO control group was inhibited by RGex administration. The ratio of $\mathrm{p}-1 \mathrm{kBa} / \mathrm{lkBa}$ expression was $1.00 \pm 0.26$ in the sham group, $2.06 \pm 0.36$ in the MCAO control group, and $1.48 \pm 0.23$ in the RGex-treated group (Fig. 6c).

Mn-SOD, also known as superoxide dismutase 2, is specifically localized to the inner membrane of mitochondria and is reportedly related to antioxidant pathways [38-40], demonstrating neuroprotective effects against oxidative stress [41-43], thus presenting a potential target for determining herbal agents with activity against ischemic brain injury. In this study, MCAO significantly increased the protein expression of Mn-SOD, and pretreatment with $1,000 \mathrm{mg} / \mathrm{kg}$ bw RGex significantly inhibited this increased expression. The expression values were $1.00 \pm 0.13$ in the sham group, $1.54 \pm 0.11$ in the MCAO control group, and $1.08 \pm 0.31$ in the RGex pretreated group (Fig. $6 \mathrm{~d}$ ).

\section{Discussion}

P. ginseng, also known as Korean ginseng, is well-known as a functional health food for vitalizing energy and eliminating chronic fatigue while improving health and has been used as a dietary supplement in Asian countries for over 2000 years [44]. P. ginseng, both red and white preparations (RG and WG, respectively), are most commonly used in traditional Korean herbal medicine, with some differences noted among them, including the ginsenoside content and pharmacological effects. RG is manufactured when WG undergoes steaming and drying [4]. During this manufacturing process, the chemical composition of ginsenosides is altered, producing bioactive compounds that have the potential to induce special physiological activities in vivo [44]. Currently, more than 30 different ginsenosides from $P$. ginseng have been isolated and characterized, and these ginsenosides are known to have different pharmacological effects [44]. However, in terms of pharmaceutical differences, comparative studies on WG and RG using animal models have not been extensively investigated. By employing network pharmacology research tools, we have recently reported that WG and RG could be efficacious in ischemic brain diseases [26], but comparative studies on the efficacy and underlying mechanisms remain scarce in ischemic stroke animal models.

Stroke is the second most common cause of death worldwide, and the most common type is ischemic stroke. Ischemic stroke is a major neurological disorder that causes physical and psychological disabilities [7-11]. As the regeneration of cerebral tissue at the time of injury is challenging, cerebrovascular damage remains intact and there is a high possibility of recurrence. Therefore, patients suffering from post-ischemic cerebral dysfunction should be prescribed suitable therapeutic agents to adjust for ongoing risk factors. Ultimately, from a pharmacological perspective, it is crucial to develop a therapeutic agent to prevent neuronal cell death, excitotoxicity, and oxidative stress, all pathways of brain cell damage [45-47]. Ischemic stroke is primarily due to metabolic diseases such as atherosclerosis, and 
the pathogenesis of ischemic stroke includes oxidative stress, inflammatory response, apoptosis, and autophagy [7-11]. Owing to the various pathogenic processes of ischemic stroke, multicomponent and multitarget agents, including traditional herbal medicine, can be effectively used to treat ischemic stroke at various stages.

Several studies have reported that treatment with ginseng or ginsenosides improves general symptoms, physical exercise capacity, and fluid metabolism in patients with coronary and myocardial ischemia and reperfusion diseases $[48,49]$. Furthermore, ginseng is reportedly used for various neuronal diseases such as neurodevelopmental, neurodegenerative, and neuropsychiatric disorders [50]. Zheng et al. have reported that ginseng total saponins improve neurological function deficits after focal cerebral ischemia by inducing endogenous neural stem cell activation, and enhance central nervous system regeneration in an MCAO rat model [51] In rats with ischemia/reperfusion-induced brain injury, Ban et al. have demonstrated that Korean RG extract showed a neuroprotective effect by reducing the level of lipid peroxidation and increasing the endogenous antioxidant enzymatic activity [52]. Recently, Liu et al. have reported that ginseng pretreatment affords protection against acute sensorimotor deficits, promoting its long-term recovery after proximal-distal MCAO in mice through nuclear factor erythroid 2-related factor 2 (Nrf2) activation [53]. Therefore, it can be assumed that WG, RG, and ginsenosides protect the brain against ischemic brain injury; however, no previous study has compared the effects of WG and RG using an animal model of ischemic stroke. Thus, in this study, the MCAO mouse model was used to compare the different effects and measure the content of ginsenoside Rg1, a representative component of ginseng, to determine whether the difference in efficacy of WGex and RGex was ginsenoside Rg1 dependent.

To observe the effects of WGex and RGex following $2 \mathrm{~h}$ of MCAO in mice, pretreatment with $1,000 \mathrm{mg} / \mathrm{kg}$ bw of RGex showed a significant reduction in \% infarct volume, but WGex showed no significant change in the dose range investigated (100 to $1,000 \mathrm{mg} / \mathrm{kg} \mathrm{bw}$ ) (Fig. 3a). Following pretreatment with WGex or RGex, the infarction volumes were reduced depending on the concentrations; although a high concentration of WGex demonstrated an effect, the effect of RGex at the same concentration (ranging from 100 to $1,000 \mathrm{mg} / \mathrm{kg} \mathrm{bw}$ ) was superior to that of WGex. On measuring the ginsenoside Rg1 content (Table 2), it was observed that WGex contained 3 times more ginsenoside Rg1 than RGex, indicating that ginsenoside Rg1 is not involved in the neuroprotective effect of RGex in the MCAO mouse model. A previous study has shown that total ginsenosides protect the brain from ischemic injury [51]; however, in this study, specific ginsenosides were considered to play a key role in specific pharmacological effects. Thus, there is a need to further investigate pharmacological activities using individual constituents. RGex pretreatment was shown to suppress brain edema but did not affect NDS changes; conversely, WGex did not affect brain edema, NDS, and rCBF changes (Fig. 3b, 3c, and Fig. S1).

To evaluate the neuroprotective effects of WGex and RGex in the cortical region of brain tissues, at a microscopic level, we used H\&E- or CV-stained frozen sections. In tissues stained with H\&E, the effects of WGex and RGex could not be confirmed (Fig. 4a); however, when stained with CV, both WGex and RGex showed significant neuroprotective effects in ischemic ipsilateral cortical neuronal cells (Fig. 4b). These 
results can be attributed to the characteristic of CV capable of specifically staining neuronal cells; on magnification, it was observed that RGex significantly inhibited cellular changes related to the inflammatory response (Fig. 5).

In this study, western blotting experiments were conducted to determine the molecular mechanism underlying the neuroprotective effects of WGex and RGex in the MCAO mouse model. iNOS plays a critical role in inflammation and apoptosis, and MAPK is an intracellular signaling molecule involved in cell migration, proliferation, and differentiation. Moreover, the MAPK pathway plays an essential role in the induction of iNOS expression [54-56]. JNK activation is associated with growth factor-mediated pathways [33-35]. In this study, the expression level of JNK was increased by MCAO induction, and pretreatment with both WGex and RGex reduced the expression level of JNK (Fig. 6b); the expression level of iNOS was regulated by RGex pretreatment (Fig. 6a). Overall, MCAO promoted the iNOS and MAPK pathways, and pretreatment with $1,000 \mathrm{mg} / \mathrm{kg}$ bw RGex altered these expressions significantly. Phosphorylated IKB proteins allow translocation of NF-KB into the nucleus, promoting inflammatory responses [36,37]. The increased expression of $\mathrm{p}-\mathrm{IkBa}$ in the MCAO control group was inhibited by RGex administration (Fig. 6c). Mn-SOD is an important potential target for identifying neuroprotective agents with efficacy against ischemic brain injury [41]. In this study, MCAO significantly increased the protein expression of Mn-SOD, and pretreatment with $1,000 \mathrm{mg} / \mathrm{kg}$ bw/day RGex significantly inhibited this increase (Fig. 6d); this indicated that antioxidative signals were activated by MCAO induction, and RGex reduced cerebral damage, thus inhibiting Mn-SOD protein expression.

In summary, both WGex and RGex protected neuronal cells in the MCAO mouse model, but the efficacy of RGex was stronger than that of WGex, and ginsenoside Rg1 was not involved in the efficacy of RGex. Mice treated with $1,000 \mathrm{mg} / \mathrm{kg}$ bw/day of RGex $1 \mathrm{~h}$ before MCAO induction revealed reduced neuronal cell death in the MCAO-induced mouse brain, and this effect was identified to be associated with antiinflammatory and anti-apoptotic pathways.

\section{Conclusions}

WGex and RGex showed neuroprotective effects in the cortical region of the MCAO-induced ischemic stroke mouse model, but the overall efficacy of RGex was stronger than that of WGex. Pretreatment with $1,000 \mathrm{mg} / \mathrm{kg}$ bw RGex significantly reduced the total infarction volume and edema area; these effects were not observed with WGex. Ginsenoside Rg1 was not considered to be involved in the effects of WGex and RGex. The protective effect of RGex in the MCAO mouse model was found to be related to antiinflammatory and anti-apoptotic pathways.

\section{Abbreviations}

ANOVA, analysis of variance; CV, cresyl violet; $\mathrm{H} \& \mathrm{E}$, hematoxylin and eosin; iNOS, inducible nitric oxide synthase; IKBa, nuclear factor of kappa light polypeptide gene enhancer in B-cells inhibitor alpha; JNK, c- 
Jun N-terminal kinase; MCA, middle cerebral artery; NDS, neurological deficit scores; tMCAO, transient middle cerebral artery occlusion; TTC, 2,3,5-triphenyl-tetrazolium chloride.

\section{Declarations}

\section{Acknowledgment}

Not applicable.

\section{Author Contributions}

Conceptualization: SC and YKK. Methodology: MJ and SC. Investigation: MJ, KMK, and SC. Data analysis: KMK and CL. Writing-Original Draft: MJ and SC. Writing-review \& editing: KMK and YKK. Supervision: KMK, SC, and YKK. All authors read and approved the final version of the manuscript.

\section{Funding}

Not applicable.

\section{Availability of data and materials}

Please contact corresponding authors for data requests.

\section{Ethics approval and consent to participate}

All procedures in this study were approved and supervised by the Ethics Committee for Animal Care and Use at Pusan National University (Approval No. PNU 2019-2485), which was certified by the Korean Association of Laboratory Animal Care.

\section{Consent for publication}

Not applicable.

\section{Declaration of Competing Interest}

The authors declare that they have no conflict of interest.

\section{Supporting Information}

Details regarding an overview of the experimental process and groups of mice for the experiment, and rCBF in all groups are available in supplementary figures (Fig. S1, S2)

\section{References}


1. Jiao L, Li B, Wang M, Liu Z, Zhang X, Liu S. Antioxidant activities of the oligosaccharides from the roots, flowers and leaves of Panax ginseng C.A. Meyer. Carbohydr Polym. 2014;106:293-8.

2. Song M, Kim B, Kim H. Influence of Panax ginseng on obesity and gut microbiota in obese middleaged Korean women. J Ginseng Res. 2014;38:106-15.

3. Choi JH, Jin SW, Park BH, Kim HG, Khanal T, Han HJ, Hwang YP, Choi JM, Chung YC, Hwang SK, Jeong TC, Jeong HG. Cultivated ginseng inhibits 2,4-dinitrochlorobenzene-induced atopic dermatitislike skin lesions in NC/nga mice and TNF-alpha/IFN-gamma-induced TARC activation in HaCaT cells. Food Chem Toxicol. 2013;56:195-203.

4. Gui Y, Ryu G. Effects of extrusion cooking on physicochemical properties of white and red ginseng (powder). J Ginseng Res. 2014;38:146-53.

5. Zhang H, Li S, Zhang H, Wang Y, Zhao ZL, Chen SL, Xu HX. Holistic quality evaluation of commercial white and red ginseng using a UPLC-QTOF-MS/MS-based metabolomics approach. J Pharm Biomed Anal. 2012;62:258-73.

6. Jung MY, Jeon BS, Bock JY. Free, esterified, and insoluble-bound phenolic acids in white and red Korean ginsengs (Panax ginseng C.A. Meyer). Food Chem. 2002;79:105-11.

7. Ingall T. Stroke-incidence, mortality, morbidity and risk. J Insur Med. 2004;36:143-52.

8. Malik S, Wong ND, Franklin SS, Kamath TV, L'Italien GJ, Pio JR, Williams GR. Impact of the metabolic syndrome on mortality from coronary heart disease, cardiovascular disease, and all causes in United States adults. Circulation. 2004;110:1245-50.

9. Mittal SH, Goel D. Mortality in ischemic stroke score: A predictive score of mortality for acute ischemic stroke. Brain Circ. 2017;3:29-34.

10. Shah B, Bartaula B, Adhikari J, Neupane HS, Shah BP, Poudel G. Predictors of in-hospital mortality of acute ischemic stroke in adult population. J Neurosci Rural Pract. 2017;8:591-4.

11. Ramirez L, Kim-Tenser MA, Sanossian N, Cen S, Wen G, He S, Mack WJ, Towfighi A. Trends in acute ischemic stroke hospitalizations in the United States. J Am Heart Assoc. 2016;5:e003233. doi: 10.1161/JAHA.116.003233.

12. Huang J, Upadhyay UM, Tamargo RJ. Inflammation in stroke and focal cerebral ischemia. Surg Neurol. 2006;66:232-45.

13. Clark RK, Lee EV, White RF, Jonak ZL, Feuerstein GZ, Barone FC. Reperfusion following focal stroke hastens inflammation and resolution of ischemic injured tissue. Brain Res Bull. 1994;35:387-92.

14. Sims NR, Muyderman H. Mitochondria, oxidative metabolism and cell death in stroke. Biochim Biophys Acta. 2010;1802:80-91.

15. Donnan GA, Fisher M, Macleod M, Davis SM. Stroke. Lancet. 2008;371:1612-23.

16. Hachinski V, Azarpazhooh MR. Stroke is a burdensome but preventable brain disorder. Lancet Neurol. 2016;15:892-3.

17. Hilbrich L, Truelsen T, Yusuf S. Stroke and cardiovascular diseases: The need for a global approach for prevention and drug development. Int J Stroke. 2007;2:104-8. 
18. Lenfant C. Can we prevent cardiovascular diseases in low- and middle-income countries? Bull World Health Organ. 2001;79:980-7.

19. Koizumi S, Yamamoto S, Hayasaka T, Konishi Y, Yamaguchi-Okada M, Goto-Inoue N, Sugiura Y, Setou $\mathrm{M}, \mathrm{Namba} \mathrm{H}$. Imaging mass spectrometry revealed the production of lyso-phosphatidylcholine in the injured ischemic rat brain. Neuroscience. 2010;168:219-25.

20. Hirayama Y, Ikeda-Matsuo Y, Notomi S, Enaida H, Kinouchi H, Koizumi S. Astrocyte-mediated ischemic tolerance. J Neurosci. 2015;35:3794-805.

21. Longa EZ, Weinstein PR, Carlson S, Cummins R. Reversible middle cerebral artery occlusion without craniectomy in rats. Stroke. 1989;20:84-91.

22. Koizumi JY, Nakazawa T, Ooneda G. Experimental studies of ischemic brain edema. I. A new experimental model of cerebral embolism in rats in which recirculation can be introduced in the ischemic area. Jpn J Stroke. 1986;8:1-8.

23. Smith HK, Russell JM, Granger DN, Gavins FN. Critical differences between two classical surgical approaches for middle cerebral artery occlusion-induced stroke in mice. J Neurosci Methods. 2015;249:99-105.

24. Dong X, Zheng L, Lu S, Yang Y. Neuroprotective effects of pretreatment of ginsenoside Rb1 on severe cerebral ischemia-induced injuries in aged mice: Involvement of anti-oxidant signaling. Geriatr Gerontol Int. 2017;17:338-45.

25. Hui Z, Sha DJ, Wang SL, Li CS, Qian J, Wang JQ, Zhao Y, Zhang JH, Cheng HY, Yang H, Yu LJ, Xu Y. Panaxatriol saponins promotes angiogenesis and enhances cerebral perfusion after ischemic stroke in rats. BMC Complement Altern Med. 2017;17:70. doi: 10.1186/s12906-017-1579-5.

26. Park $S$, Lee $B$, Jin M, Cho S. Comparison of network pharmacology based analysis on White Ginseng and Red Ginseng. Herb Formula Sci. 2020;28:243-54.

27. Lee SE, Lim C, Lee M, Kim CH, Kim H, Lee B, Cho S. Assessing neuroprotective effects of Glycyrrhizae Radix et Rhizoma extract using a transient middle cerebral artery occlusion mouse model. J Vis Exp. 2018;142. doi:10.3791/58454.

28. Alderton WK, Cooper CE, Knowles RG. Nitric oxide synthases: Structure, function and inhibition. Biochem J. 2001;357:593-615. doi: 10.1042/0264-6021:3570593.

29. Beckman JS, Beckman TW, Chen J, Marshall PA, Freeman BA. Apparent hydroxyl radical production by peroxynitrite: Implications for endothelial injury from nitric oxide and superoxide. Proc Natl Acad Sci USA. 1990;87:1620-24.

30. Moncada S, Higgs EA. Endogenous nitric oxide: Physiology, pathology and clinical relevance. Eur J Clin Invest. 1991;21:361-74.

31. Guo C, Yang M, Jing L, Wang J, Yu Y, Li Y, Duan J, Zhou X, Li Y, Sun Z. Amorphous silica nanoparticles trigger vascular endothelial cell injury through apoptosis and autophagy via reactive oxygen species-mediated MAPK/Bcl-2 and PI3K/Akt/mTOR signaling. Int J Nanomedicine. 2016;11:5257-76. 
32. Li L, Du JK, Zou LY, Wu T, Lee YW, Kim YH. Decursin isolated from Angelica gigas Nakai rescues PC12 cells from amyloid beta-protein-induced neurotoxicity through Nrf2-mediated upregulation of heme oxygenase-1: Potential roles of MAPK. Evid Based Complement Alternat Med. 2013;2013:467245. doi: 10.1155/2013/467245.

33. Chuang SM, Wang IC, Yang JL. Roles of JNK, p38 and ERK mitogen-activated protein kinases in the growth inhibition and apoptosis induced by cadmium. Carcinogenesis. 2000;21:1423-32.

34. Chuang SM, Liou GY, Yang JL. Activation of JNK, p38 and ERK mitogen-activated protein kinases by chromium $(\mathrm{VI})$ is mediated through oxidative stress but does not affect cytotoxicity. Carcinogenesis. 2000;21:1491-500.

35. Plotnikov A, Zehorai E, Procaccia S, Seger R. The MAPK cascades: Signaling components, nuclear roles and mechanisms of nuclear translocation. Biochim Biophys Acta. 2011;1813:1619-33.

36. Dorrington MG, Fraser IDC. NF-kB signaling in macrophages: Dynamics, crosstalk, and signal integration. Front Immunol. 2019;10:705. doi: 10.3389/fimmu.2019.00705.

37. Liu T, Zhang L, Joo D, Sun SC. NF-kB signaling in inflammation. Signal Transduct Target Ther. 2017;2:17023. doi: 10.1038/sigtrans.2017.23.

38. Ambe K, Watanabe H, Takahashi S, Nakagawa T. Immunohistochemical localization of Nox1, Nox4 and Mn-SOD in mouse femur during endochondral ossification. Tissue Cell. 2014;46:433-8.

39. Kinoshita M, Sakamoto T, Kashio A, Shimizu T, Yamasoba T. Age-related hearing loss in Mn-SOD heterozygous knockout mice. Oxid Med Cell Longev. 2013;2013:325702. doi: 10.1155/2013/325702.

40. Lu X, Wang C, Liu B. The role of Cu/Zn-SOD and Mn-SOD in the immune response to oxidative stress and pathogen challenge in the clam Meretrix meretrix. Fish Shellfish Immunol. 2015;42:58-65.

41. Jung JE, Kim GS, Narasimhan P, Song YS, Chan PH. Regulation of Mn-superoxide dismutase activity and neuroprotection by STAT3 in mice after cerebral ischemia. J Neurosci. 2009;29:7003-14.

42. Scorziello A, Santillo M, Adornetto A, Dell'aversano C, Sirabella R, Damiano S, Canzoniero LMT, Di Renzo GF, Annunziato L. NO-induced neuroprotection in ischemic preconditioning stimulates mitochondrial Mn-SOD activity and expression via Ras/ERK1/2 pathway. J Neurochem. 2007;103:1472-80.

43. Garnier P, Demougeot C, Bertrand N, Prigent-Tessier A, Marie C, Beley A. Stress response to hypoxia in gerbil brain: HO-1 and Mn SOD expression and glial activation. Brain Res. 2001;893:301-9.

44. Ramesh T, Kim S, Hwang S, Sohn S, Yoo S, Kim S. Panax ginseng reduces oxidative stress and restores antioxidant capacity in aged rats. Nutr Res. 2012;32:718-26.

45. Gu Z, Kaul M, Yan B, Kridel SJ, Cui J, Strongin A, Smith JW, Liddington RC, Lipton SA. S-nitrosylation of matrix metalloproteinases: Signaling pathway to neuronal cell death. Science. 2002;297:1186-90.

46. Sattler R, Tymianski M. Molecular mechanisms of glutamate receptor-mediated excitotoxic neuronal cell death. Mol Neurobiol. 2001;24:107-29.

47. Dunn KM, Renic M, Flasch AK, Harder DR, Falck J, Roman RJ. Elevated production of 20-HETE in the cerebral vasculature contributes to severity of ischemic stroke and oxidative stress in spontaneously 
hypertensive rats. Am J Physiol Heart Circ Physiol. 2008;295:H2455-65. doi:

10.1152/ajpheart.00512.2008.

48. Tsutsumi YM, Tsutsumi R, Mawatari K, Nakaya Y, Kinoshita M, Tanaka K, Oshita S. Compound K, a metabolite of ginsenosides, induces cardiac protection mediated nitric oxide via Akt/PI3K pathway. Life Sci. 2011;88:725-9.

49. Zhang D, Yasuda T, Yu Y, Zheng P, Kawabata T, Ma Y, Okada S. Ginseng extract scavenges hydroxyl radical and protects unsaturated fatty acids from decomposition caused by iron-mediated lipid peroxidation. Free Radic Biol Med. 1996;20:145-50.

50. Kim HJ, Kim P, Shin CY. A comprehensive review of the therapeutic and pharmacological effects of ginseng and ginsenosides in central nervous system. J Ginseng Res. 2013;37:8-29.

51. Zheng GQ, Cheng W, Wang Y, Wang XM, Zhao SZ, Zhou Y, Liu SJ, Wang XT. Ginseng total saponins enhance neurogenesis after focal cerebral ischemia. J Ethnopharmacol. 2011;133:724-8.

52. Ban JY, Kang SW, Lee JS, Chung JH, Ko YG, Choi HS. Korean red ginseng protects against neuronal damage induced by transient focal ischemia in rats. Exp Ther Med. 2012;3:693-8.

53. Liu L, Vollmer MK, Fernandez VM, Dweik Y, Kim H, Doré S. Korean red ginseng pretreatment protects against long-term sensorimotor deficits after ischemic stroke likely through Nrf2. Front Cell Neurosci. 2018;12:74. doi: 10.3389/fncel.2018.00074.

54. Gao X, Zhang H, Takahashi T, Hsieh J, Liao J, Steinberg GK, Zhao H. The Akt signaling pathway contributes to postconditioning's protection against stroke; the protection is associated with the MAPK and PKC pathways. J Neurochem. 2008;105:943-55.

55. Sawe N, Steinberg G, Zhao H. Dual roles of the MAPK/ERK1/2 cell signaling pathway after stroke. J Neurosci Res. 2008;86:1659-69.

56. Sun J, Nan G. The mitogen-activated protein kinase (MAPK) signaling pathway as a discovery target in stroke. J Mol Neurosci. 2016;59:90-8.

\section{Tables}

Table 1. Analytical condition of gradients. Acetonitrile (A) and water (B) were used for the mobile phase by gradient elution.

\begin{tabular}{|lll|}
\hline Time $(\mathrm{min})$ & Mobile phase A (Vol\%) & Mobile phase B (Vol\%) \\
\hline 0 & 20 & 80 \\
\hline 5 & 20 & 80 \\
\hline 15 & 50 & 50 \\
\hline 20 & 50 & 50 \\
\hline
\end{tabular}


Table 2. Quantitative measurement of the standard compound, ginsenoside Rg1, in ginseng extracts

\begin{tabular}{|lllll|}
\hline Extract & $\lambda_{\max }(\mathrm{nm})$ & $\mathrm{t}_{\mathrm{R}}(\mathrm{min})$ & $\mathrm{r}^{2}$ & Amount of ginsenoside Rg1 $(\mathrm{ppm})$ \\
\hline WGex & 203 & 14.86 & 0.9982 & 145.03 \\
\cline { 3 - 4 } & & & & 48.71 \\
\hline
\end{tabular}

WGex, methanolic extract of white ginseng; RGex, methanolic extract of red ginseng.

\section{Figures}

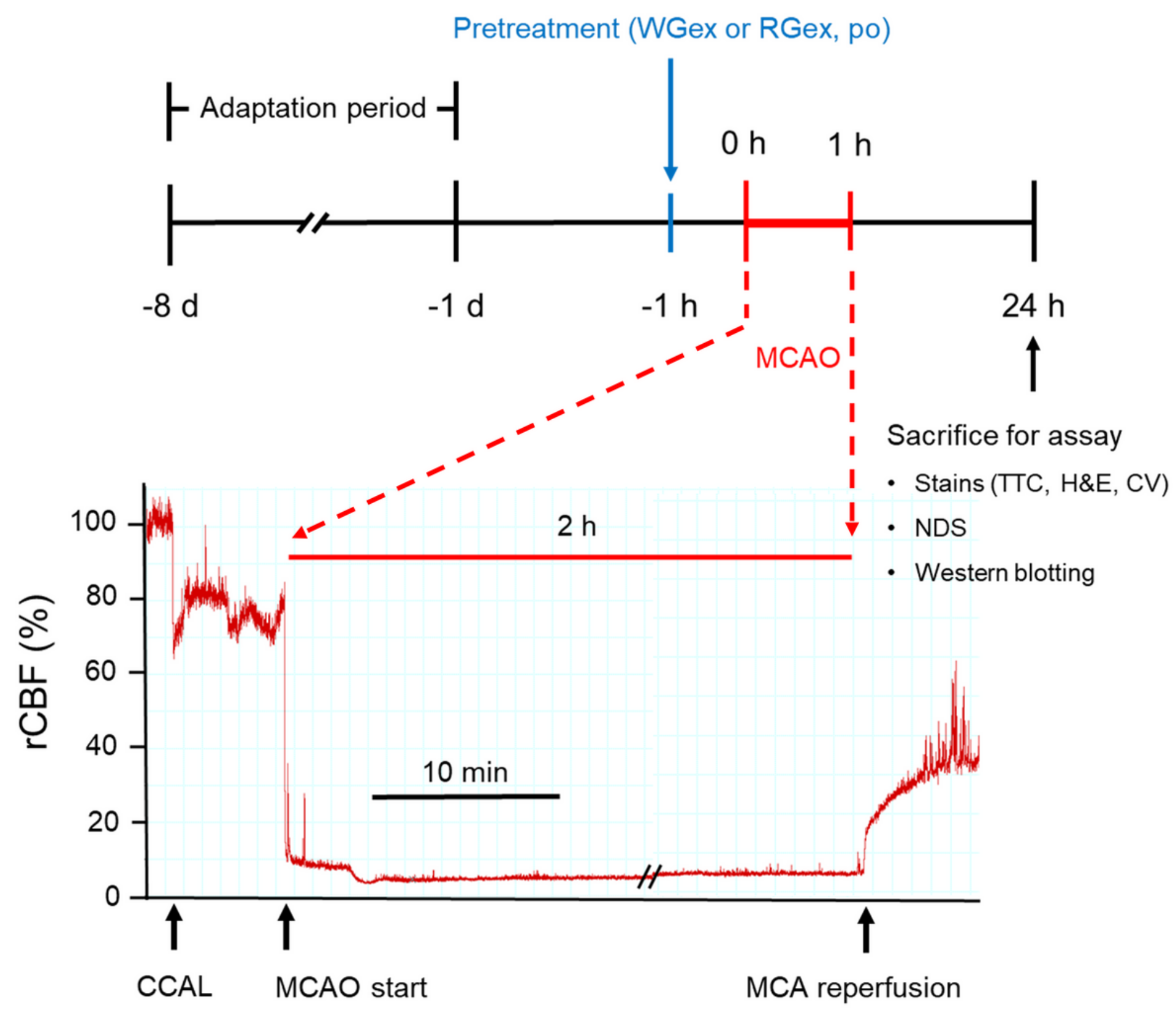

Figure 1 
Experimental design in $2 \mathrm{~h}$ transient middle cerebral artery occlusion (tMCAO) model. Ischemic stroke model in mice. Mice were adapted for seven days at animal facilities. Pretreatment (per os, po) was performed to compare the efficacies of ginseng extracts (methanolic extract of white ginseng and red ginseng; WGex and RGex, respectively). TTC, 2,3,5-triphenyl-tetrazolium chloride; H\&E, hematoxylin and eosin; CV, cresyl violet; NDS, neurological deficit scores; rCBF, relative cerebral blood flow; CCAL, common carotid artery ligation.
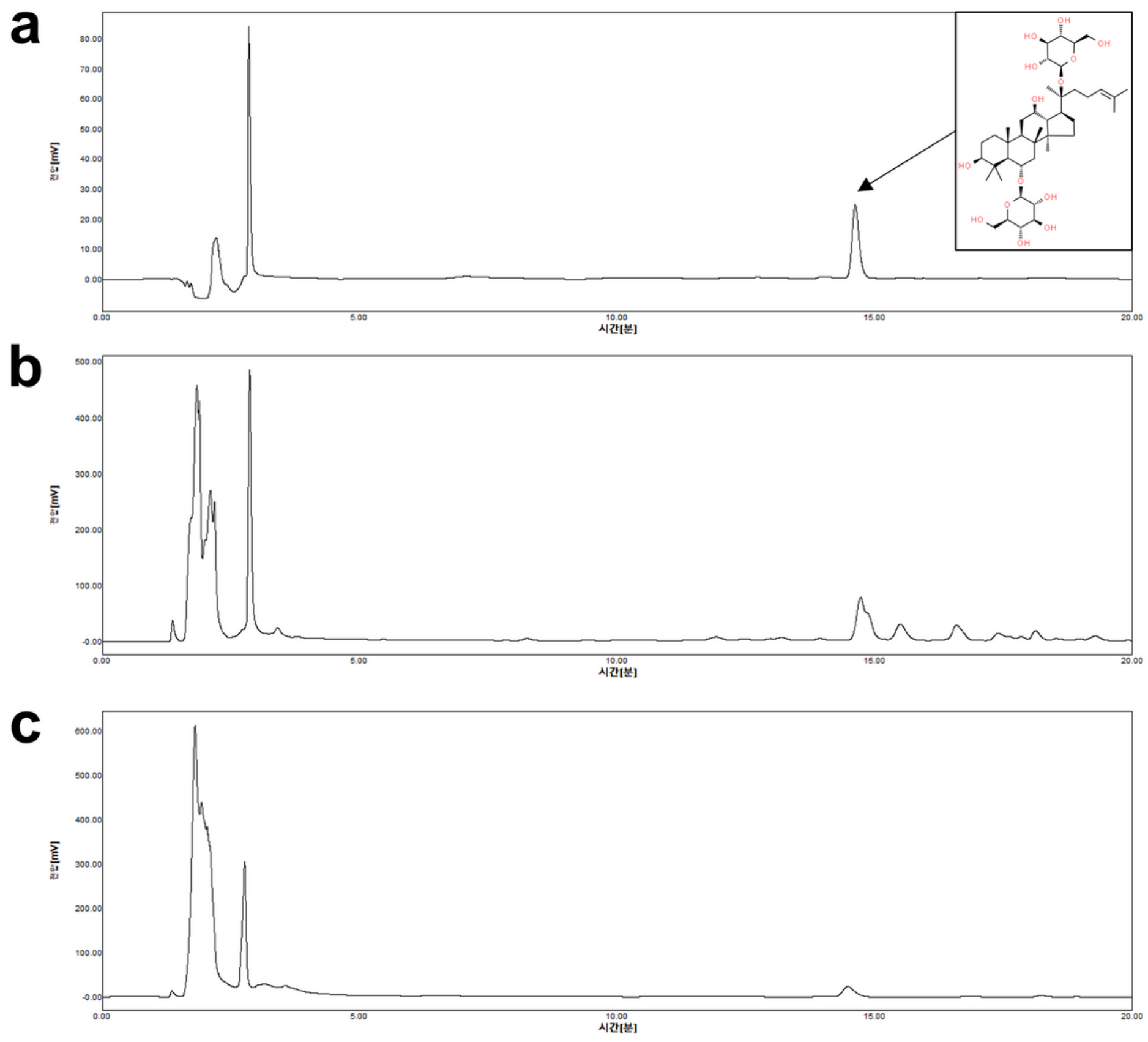

\section{Figure 2}

Chromatograms of WGex and RGex and their standard, ginsenoside Rg1, following high-performance chromatography (HPLC). a, HPLC profile of ginsenoside Rg1 and its chemical structures; $b$ and c, HPLC profile of ginseng extracts (b, WGex; c, RGex). HPLC, Shimadzu system (Shimadzu, Kyoto, Japan); 
column, YMC-Triart C18; wavelength, $203 \mathrm{~nm}$; column temperature, $25^{\circ} \mathrm{C}$; flow rate, $1 \mathrm{~mL} / \mathrm{min}$; injection volume, $10 \mu \mathrm{L}$. WGex, methanolic extract of white ginseng; RGex, methanolic extract of red ginseng.

\section{a}
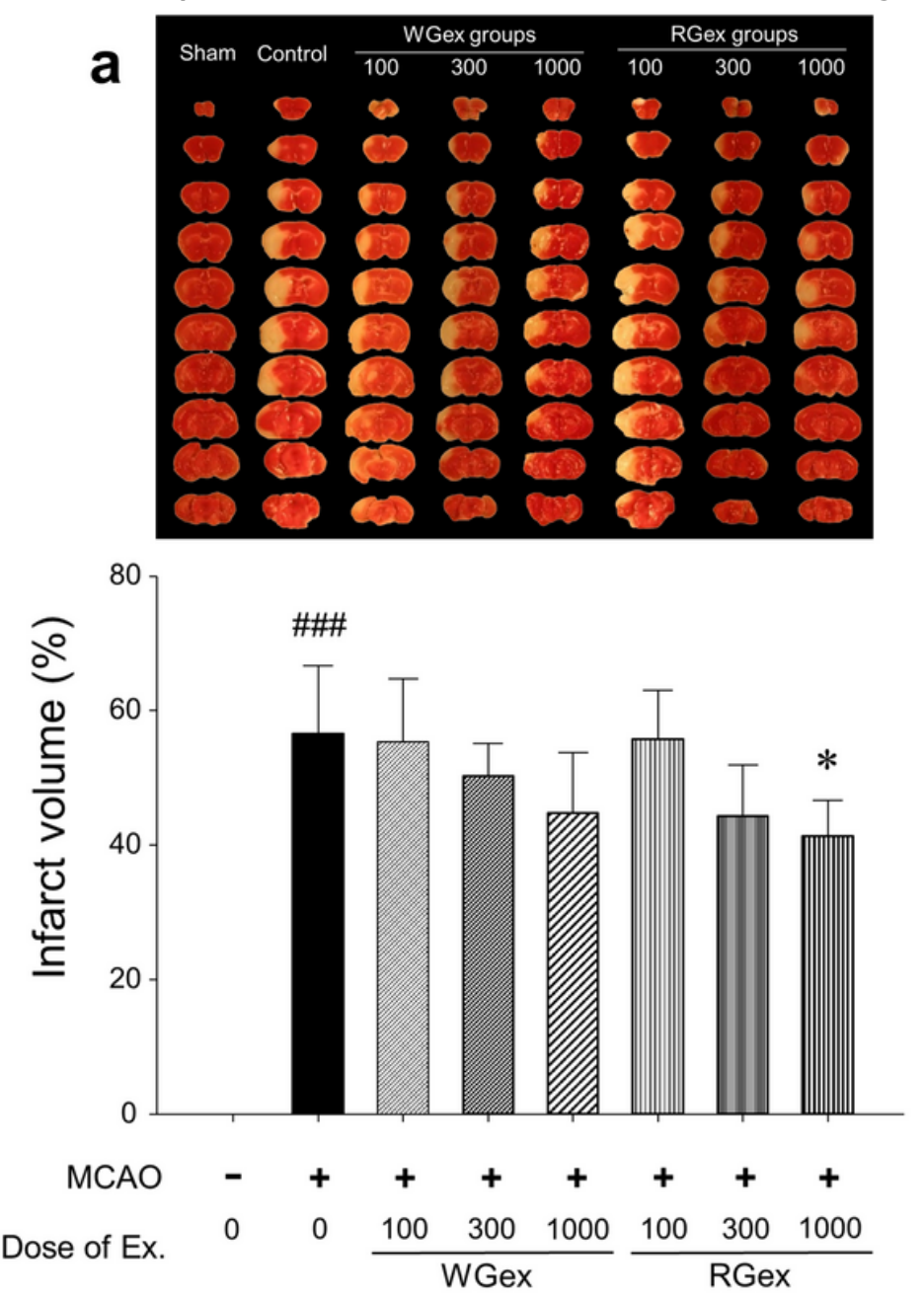

b

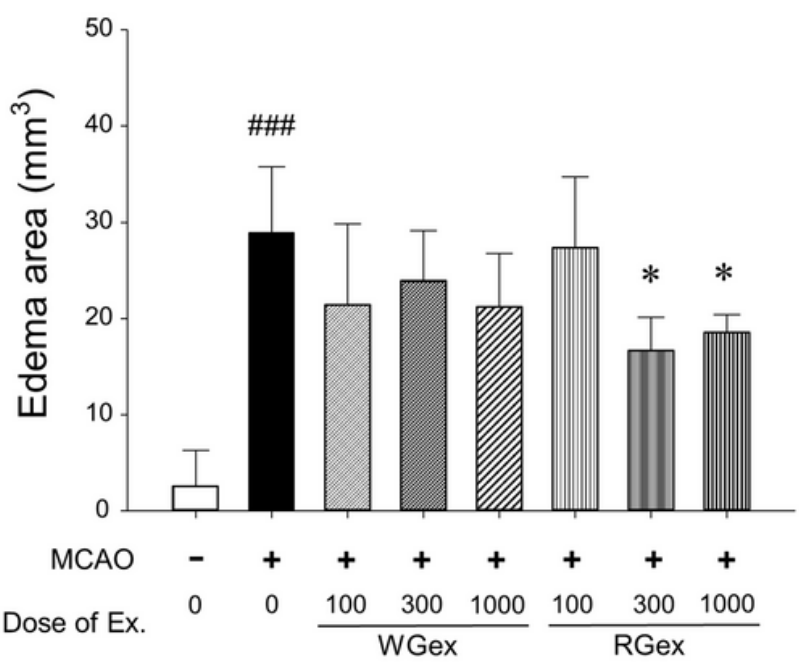

C

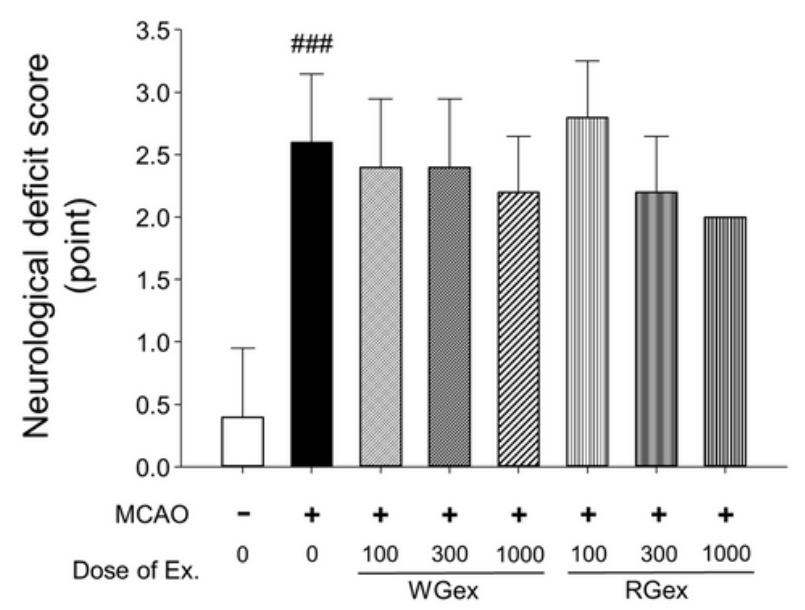

Figure 3

Measurements of infarct volume, edema area, and neuronal deficit score (NDS). a, representative photographs of TTC-stained brain slices $(1 \mathrm{~mm}$ ) showing the infarct area $24 \mathrm{~h}$ after MCAO (upper column) and quantitative analysis of the total infarct volume (lower column). b, quantitative analysis of the edema area, calculated by dividing total infarction volumes in ipsilateral hemispheres by brain edema indices using TTC-stained brain slice. $c$, quantitative analysis of NDS. All data expressed as means \pm standard deviation (SD) $(n=5)$. \#\#\# $p<0.001$ vs. sham group and * $p<0.05$ vs. MCAO control group. TTC, 2,3,5-triphenyl-tetrazolium chloride; MCAO, middle cerebral artery occlusion; NDS, neurological deficit scores. 
a
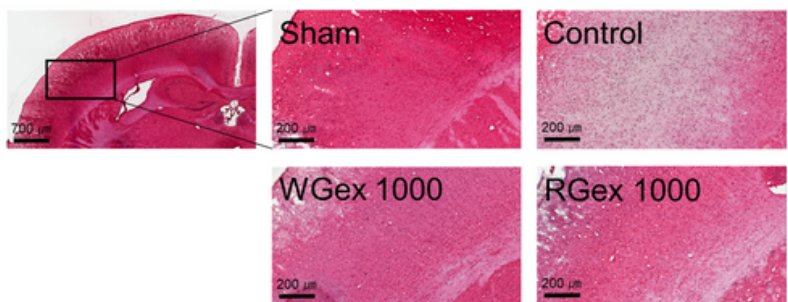

RGex 1000
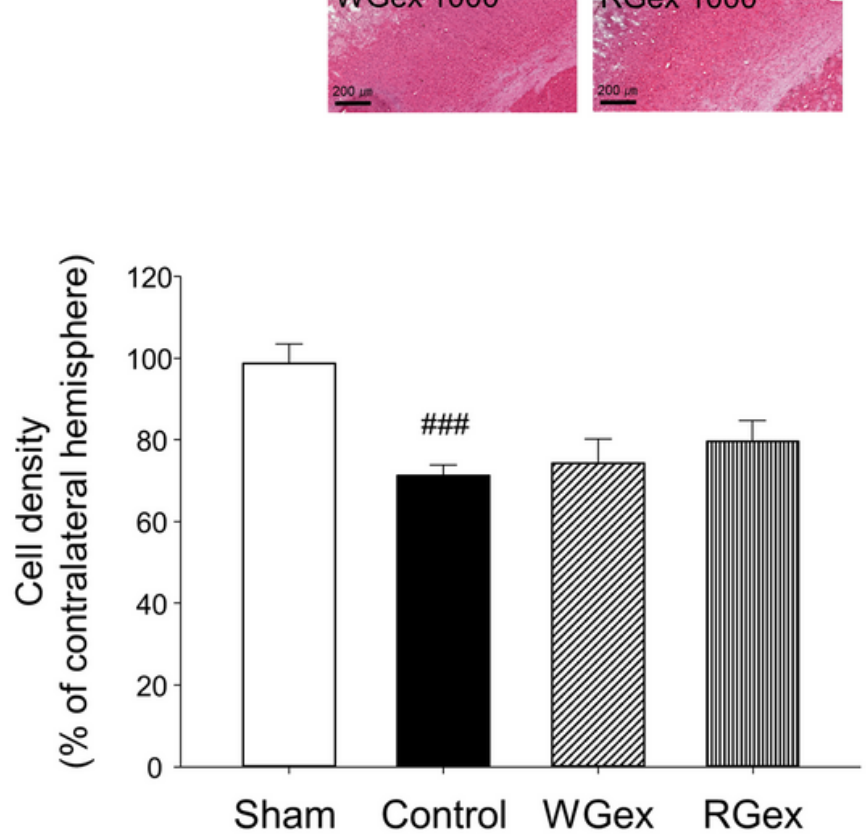

b
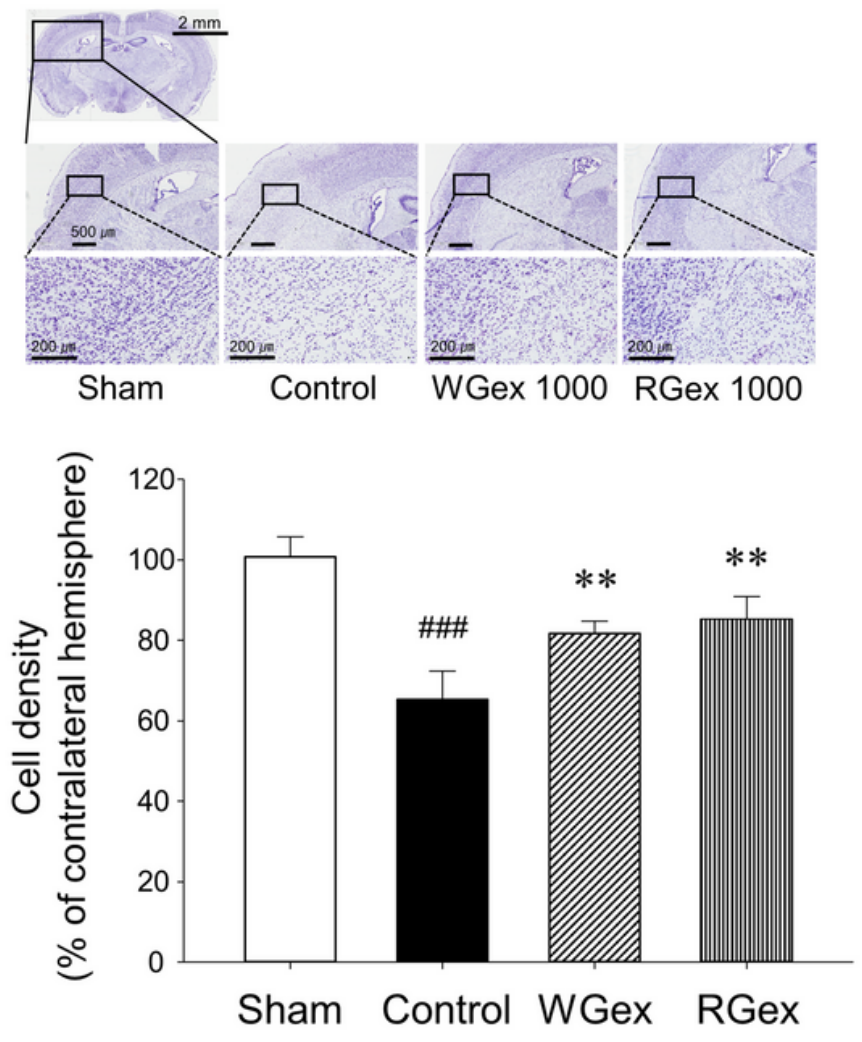

\section{Figure 4}

Neuroprotective effects of ginseng extracts on MCAO-induced cell death. a, Representative photomicrographs of hematoxylin and eosin (H\&E)-stained sections (upper column) and quantitative analysis showing changes in the number of cells (lower column). b, Representative photomicrographs of cresyl violet (CV)-stained sections (upper column) and quantitative analysis showing changes in the number of cells (lower column). All data expressed as means \pm standard deviation (SD) $(n=5)$. \#\#\# $p<$ 0.001 vs. sham group and $* \star p<0.01$ vs. MCAO control group. MCAO, middle cerebral artery occlusion. 

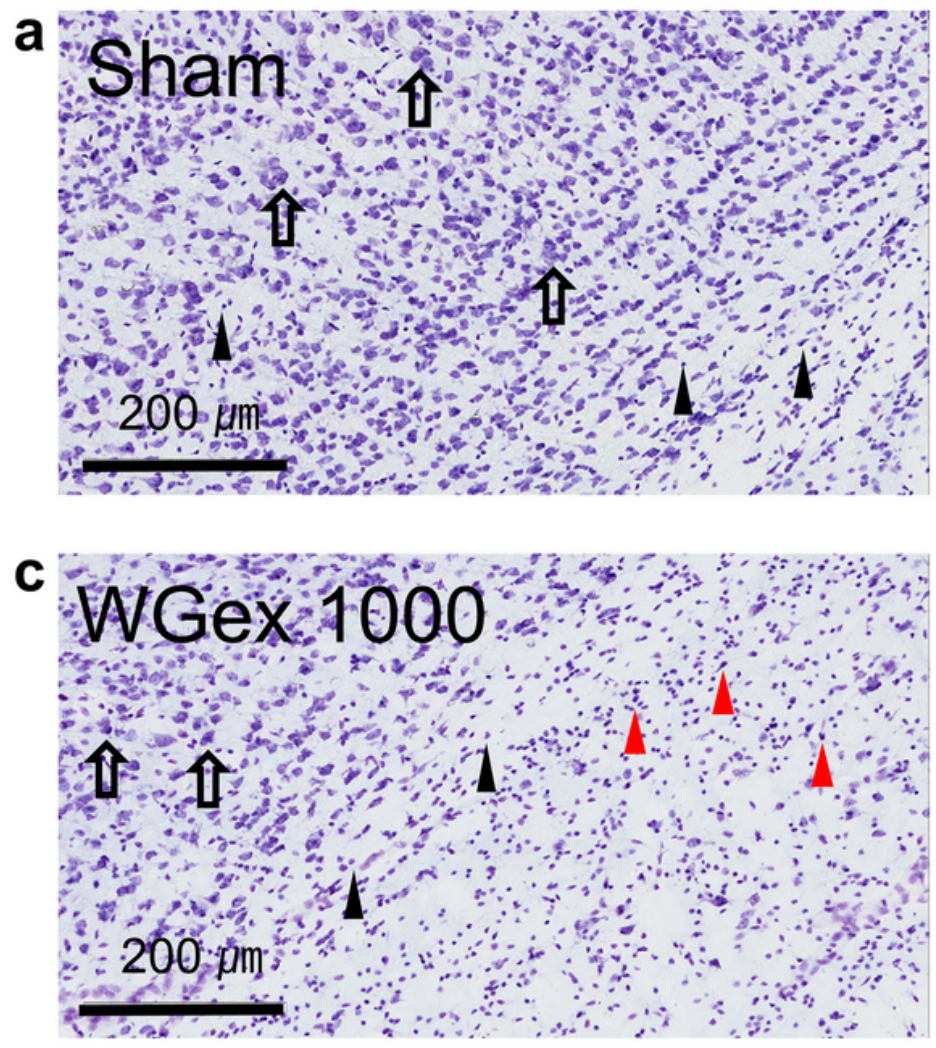

bontrof
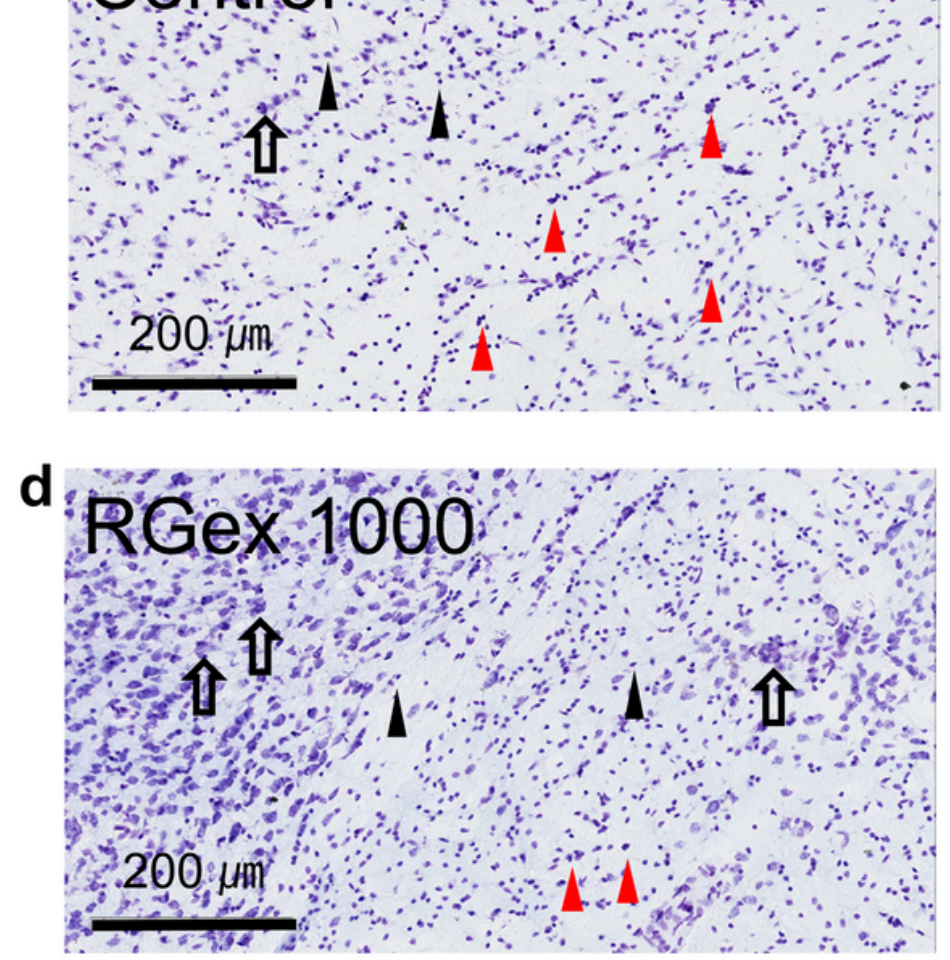

Figure 5

Morphological changes in the cortical area of ischemic ipsilateral hemispheres. Each photomicrograph represents CV-stained cortical regions. Arrows indicate normal neurons, black arrowheads represent glial cells in the resting state, and red arrowheads represent activated glial cells. Scale bars, $200 \mu \mathrm{m}$. CV, cresyl violet. 
a
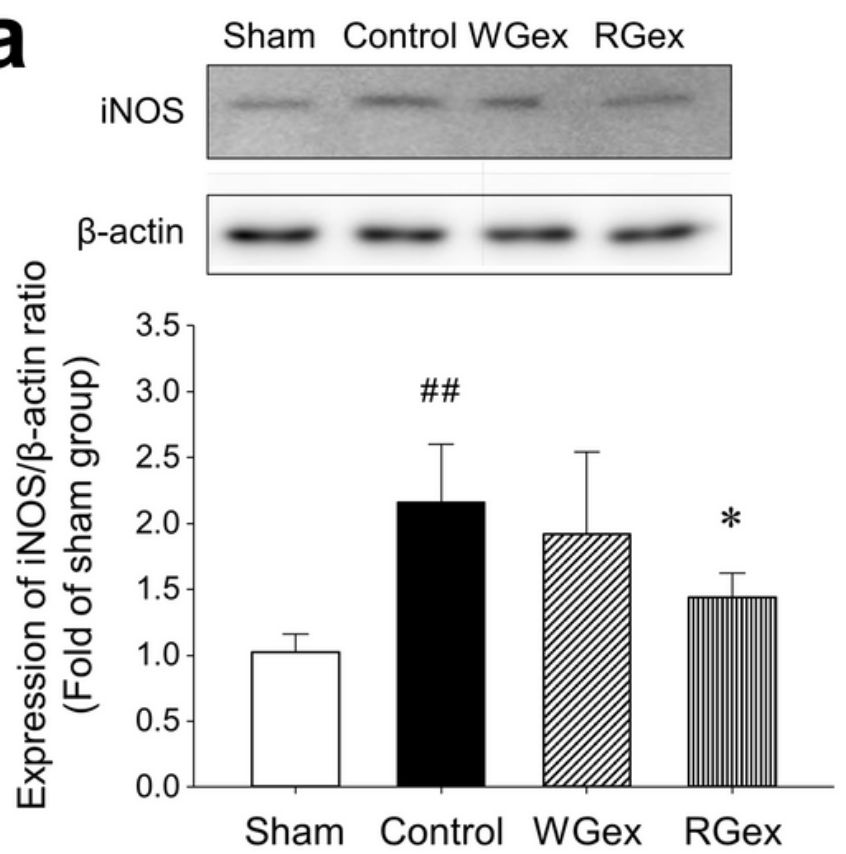

C

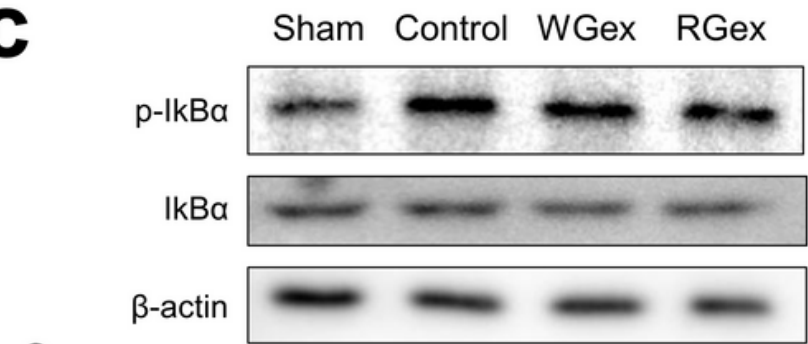

음

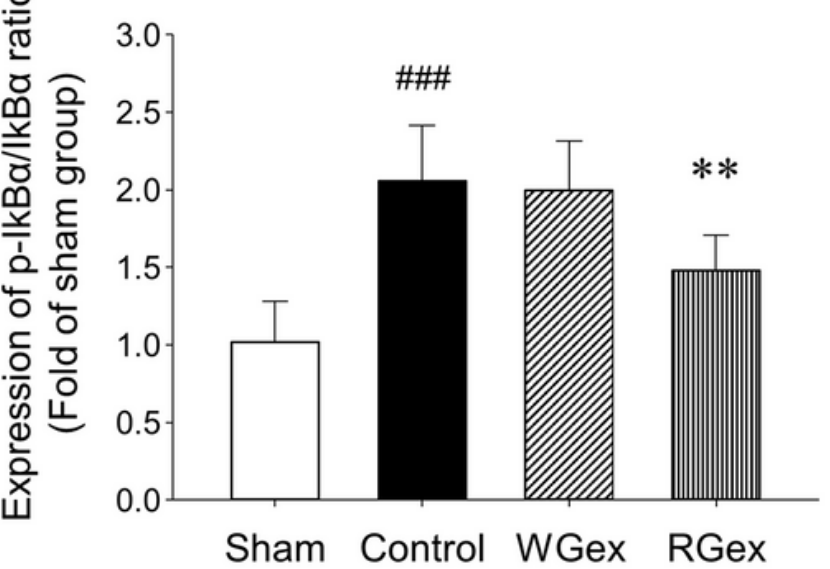

b

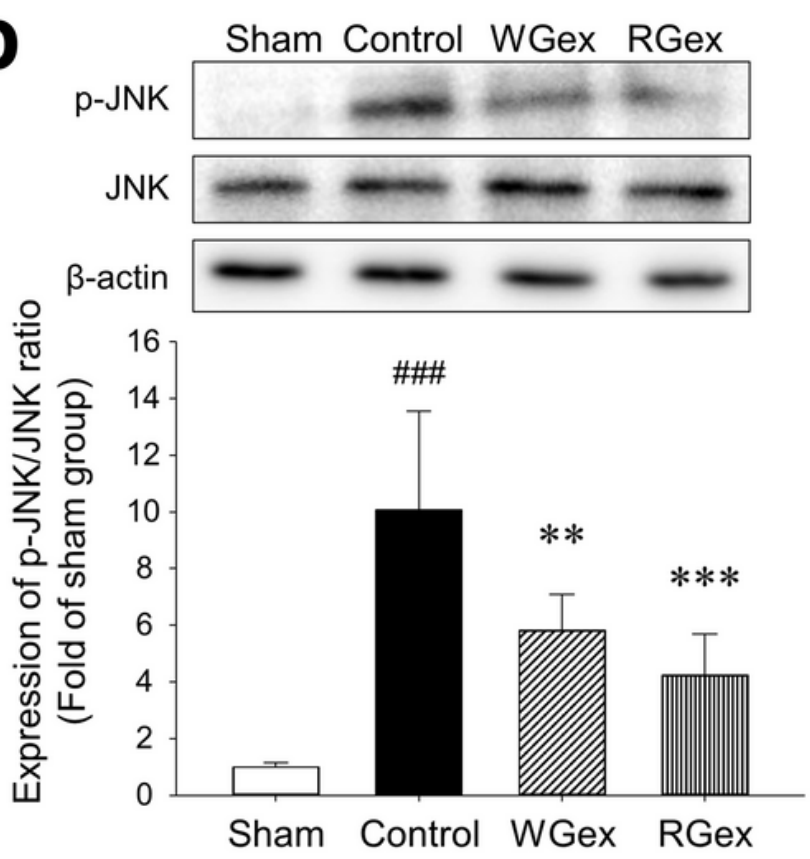

d Sham Control WGex RGex

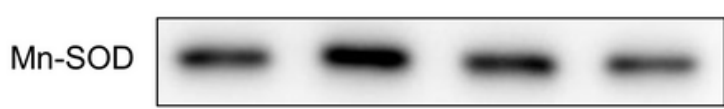

$\beta$-actin
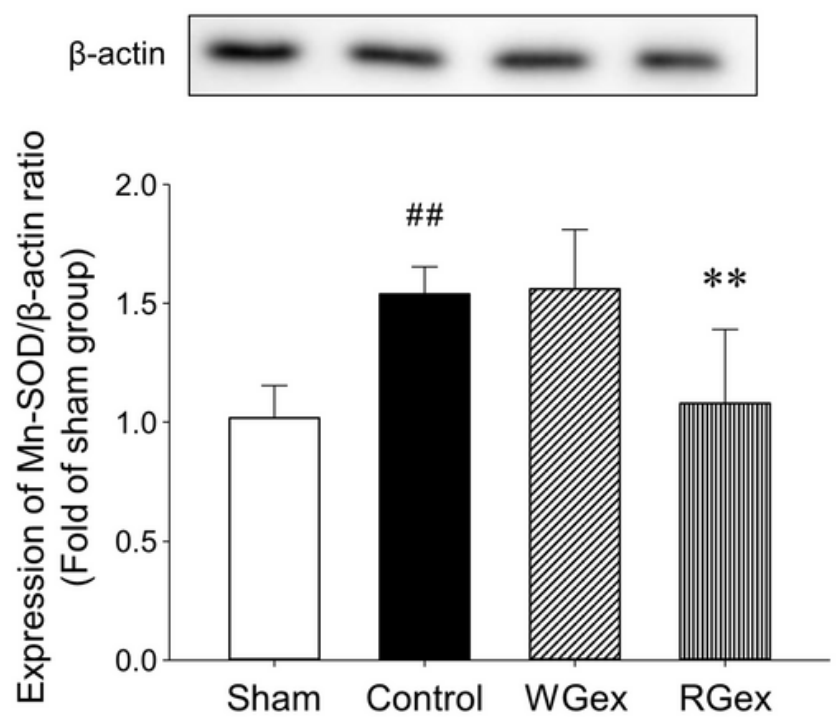

\section{Figure 6}

Effects of pretreatment with WGex and RGex on changes in iNOS, p-JNK, p-IkBa, and Mn-SOD proteins analysis in MCAO induced mouse brain. Representative images (upper column of a, b, c, and d) and relative densitometry (lower column of $a, b, c$, and d) of western blot analysis of expression levels of each protein and $\beta$-actin in brain tissues ( $n=5$ experiments). All data expressed as means \pm standard deviation (SD). \#\# $p<0.01$ vs. sham group, \#\#\# $p<0.001$ vs. sham group, ${ }^{\star} p<0.05$ vs. MCAO control group, ${ }^{\star \star} p$ 
$<0.01$, and ${ }^{\star * \star} p<0.001$ vs. MCAO control group. WGex, methanolic extract of white ginseng; RGex, methanolic extract of red ginseng; iNOS, inducible nitric oxide; $\mathrm{p}$-JNK, phospho-c-Jun N-terminal kinase; $\mathrm{p}$ IKBa, p-nuclear factor of kappa light polypeptide gene enhancer in B-cells inhibitor alpha; Mn-SOD, manganese superoxide dismutase.

\section{Supplementary Files}

This is a list of supplementary files associated with this preprint. Click to download.

- FigureS1.tif

- Figures2.tif

- GraphicalAbstract.tif 